\title{
Analysis of the Influence of Precipitation and Wind on PM2.5 and PM10 in the Atmosphere
}

\author{
Zhen Liu, ${ }^{1,2}$ Luming Shen, ${ }^{1,2}$ Chengyu Yan $\mathbb{D}^{1,2}$ Jianshuang Du, $^{1,2}$ Yang Li, $^{1,2}$ and Hui Zhao ${ }^{3}$ \\ ${ }^{1}$ Key Laboratory of Meteorology and Ecological Environment of Hebei Province, Shijiazhuang 050000, China \\ ${ }^{2}$ Qinhuangdao Meteorological Bureau, Qinhuangdao 066000, China \\ ${ }^{3}$ Key Laboratory for Aerosol-Cloud-Precipitation of China Meteorological Administration, \\ Nanjing University of Information Science and Technology, Nanjing 210044, China \\ Correspondence should be addressed to Chengyu Yan; chengyu_yangaogong@163.com
}

Received 22 January 2020; Revised 9 April 2020; Accepted 7 May 2020; Published 3 August 2020

Academic Editor: Marina Baldi

Copyright (C) 2020 Zhen Liu et al. This is an open access article distributed under the Creative Commons Attribution License, which permits unrestricted use, distribution, and reproduction in any medium, provided the original work is properly cited.

\begin{abstract}
In this paper, hourly observations of precipitation, wind, and PM2.5 and PM10 concentrations in Qinhuangdao from 2016 to 2018 were used to study the effects of precipitation and wind on PM2.5 and PM10 concentrations. The results show that precipitation has a certain wet scavenging effect on PM2.5 and PM10, and the scavenging effect on PM10 is greater than that on PM2.5. Precipitation above moderate rainfall is concentrated from May to September, and light rain in winter increases the concentration of pollutants. The changes of PM2.5 before and after precipitation are related to the initial concentration of PM2.5 before precipitation, precipitation intensity, and precipitation duration. The scavenging effect of precipitation on PM10 is closely related to the initial concentration of PM10 before precipitation. The higher the initial concentration of PM10 is, the greater the removal amount of precipitation will be. Moderate or above pollution weather mainly occurs in the northeast, southwest, and west wind meteorological conditions; the more westerly the wind, the more the pollution; north wind and northwest wind have the most obvious scavenging effect on PM2.5 and Pm10; when the wind speed increases to $2 \mathrm{~m} / \mathrm{s}$, the concentration of PM2.5 and PM10 can be reduced; when the wind speed is more than $4 \mathrm{~m} / \mathrm{s}$, the concentration of PM10 increases under the south wind, southeast wind, east wind, and northeast wind.
\end{abstract}

\section{Introduction}

With the rapid development of industrialization, social economy, and the increasing number of motor vehicles, the problem of urban air pollution has become more and more serious, which has become an important factor restricting the construction of urban ecological civilization $[1,2]$. Among them, atmospheric particulate matter is the primary pollutant causing this environmental problem. Atmospheric particulate matter mainly includes particulate matter PM2.5 (the particulate matter with aerodynamic diameter less than or equal to $2.5 \mu \mathrm{m}$ ) and PM10 (the particulate matter with aerodynamic diameter less than or equal to $10 \mu \mathrm{m}$ ), and the excessive concentration of particulate matter has become a prominent problem in the air quality of many cities in China [3-7]. It will reduce the visibility of the atmosphere, cause harm to human body, and may lead to diseases related to heart and lung dysfunction $[8,9]$. Therefore, the research on management of PM2.5 and PM10 has become a hot topic in recent years. Besides, it is found to significantly affect the cloud formation and precipitation through aerosol-radiation interaction or aerosol-cloud interaction [10-14], even though the net effect remains highly debated [15-17]. The main factors affecting the concentration of atmospheric particulate matter include emission sources and meteorological factors [18-24]. When the pollution source is relatively stable, the influence of meteorological conditions on particle concentration plays a leading role $[25,26]$. Both of them affect the wet removal process and dry removal process of particulate matter, respectively, which is an important process to maintain the balance of the source and sink suspended particles in the atmosphere and the self-cleaning 
of the atmosphere. The removal ability of precipitation and wind is an important indicator for the improvement of air quality in polluted weather conditions.

Many scholars studied the relationship between PM2.5 and PM10 concentrations and precipitation in different regions and found that the removal effect of precipitation on aerosol particles was related to precipitation intensity, raindrop diameter, and aerosol particle size. The scavenging efficiency of large particles changed significantly with the change of raindrop diameter, while the removal coefficient of small particles was less affected by the diameter of raindrop [27]. Other scholars believe that the effect of precipitation on the wet removal of PM10 and PM2.5 is enhanced with the increase of total rainfall, average rainfall intensity, and precipitation duration $[28,29]$. Also many scholars explore the role of precipitation cloud clearance from the perspective of atmospheric observation [30-32], It is believed that precipitation has different scavenging effects on aerosol with different particle sizes, and the wet scavenging effects of precipitation on medium size aerosol are not ideal, but it has obvious settling effects on large size aerosol and small size aerosol [33-36]. It can be seen that the removal mechanism of pollutants by precipitation is highly uncertain.

Wind also has an important influence on the level of air pollution. Many scholars have analyzed the wind removal capacity of different cities in China. Influenced by topography, geographical location, and climatic conditions, the dominant wind direction affecting particle concentration varies greatly in different regions [37, 38]. Recent studies [39] indicated that wind shear seems much more important, if not equally, than wind speed in modulating ground surface PM2.5 concentration. Qinhuangdao is located in the eastern part of the Beijing-Tianjin-Hebei region. It was one of the low-carbon pilot cities and the country's top 10 cities for ecological civilization in China. Air pollution not only is caused by local accumulation, but also is mainly affected by external transportation. Previous studies lack analysis and research on the long series observation data in Qinhuangdao area, and the monitoring results of particulate matter concentration show that there is often decrease in particulate matter concentration after precipitation. Therefore, it is necessary to classify and analyze the actual clearing law of precipitation and wind factors that often occur in the weather process of Qinhuangdao and give quantitative indexes. Under the weather condition of unfavorable diffusion, the fine service of pollutant concentration is more needed, which is conducive to the exploration of key weather condition forecast indexes. It provides a reference basis for the further improvement of air pollution forecast, warning, and prevention.

\section{Data and Methods}

2.1. Ground-Based Meteorological Observations. The data of precipitation, wind direction, and wind speed in this paper are hourly data from Qinhuangdao meteorological observation station in China. The research period is from January 2016 to December 2018. The hourly rainfall intensity involved in the research is the total precipitation in a precipitation process divided by the duration of precipitation. According to the classification standard of meteorological department, the precipitation grade is divided into light rain, moderate rain, heavy rain, torrential rain, heavy rainstorm, and extraordinary rainstorm. The corresponding precipitations $(\mathrm{mm})$ for 24 hours are 0.1-9.9, 10-24.9, 25-49.9, $50-99.9,100-249.9$, and greater than or equal to 250 .

\subsection{Environmental Meteorological Information. This paper} makes use of PM2.5 and PM10 concentration observation data from January 2016 to December 2018 at a time resolution of 1 hour, and the data are derived from the environmental meteorological data of the meteorological information sharing platform in Hebei Province of China. Qinhuangdao city PM2.5 and PM10 concentration detection site has a city monitoring station, Beidaihe Environmental Protection Bureau station, Tiguan station, the construction of buildings station, Wenming Li station, Shanhaiguan district government station, and Beidaihe District Committee of the old cadres Bureau station, a total of 7 urban monitoring stations.

According to the national environmental protection standards of People's Republic of China hj633-2012, air quality is divided into excellent, good, light pollution, moderate pollution, heavy pollution, serious pollution, and off the charts which corresponds to the PM10 mass concentration of PM10 in the air $\left(\mu \mathrm{g} / \mathrm{m}^{3}\right)$, respectively, $0-50$, $51-150,151-250,251-350,351-420,421-600$, and $>600$. The mass concentration of PM2.5 $\left(\mu \mathrm{g} / \mathrm{m}^{3}\right)$ in the air is $0-35$, $36-75,76-115,116-150,151-250,251-500$, and $>500$.

\section{Results and Discussions}

\subsection{Monthly Distribution Characteristics of Precipitation and} Mass Concentration of PM2.5 and PM10 in Qinhuangdao. In order to study the correspondence between monthly precipitation and average PM2.5 and PM10 in Qinhuangdao city of China (Figure 1), the distribution characteristics of monthly precipitation and average mass concentration of PM2.5 and PM10 (Figure 2) in Qinhuangdao from January 2016 to December 2018 and the distribution of precipitation days of different orders of magnitude in each month were statistically analyzed (Figure 3). Due to Qinhuangdao's geographical location, winter is longer; according to the local spring, summer, autumn, and winter season statistics, the four seasons of Qinhuangdao are divided into spring from April to May, summer from June to August, autumn from September 1 to November 14, and winter from November 15 to March the following year.

Qinhuangdao city's average precipitation for the three years is $641.7 \mathrm{~mm}$; according to Qinhuangdao city climate bulletin, the average annual precipitation range of Qinhuangdao from 1981 to 2010 is $452-753 \mathrm{~mm}$, so the average annual precipitation in Qinhuangdao city 2016-2018 is a normal year. Qinhuangdao city's precipitation has obvious monthly variation characteristics; precipitation is mainly concentrated in June, July, and August, including the annual 


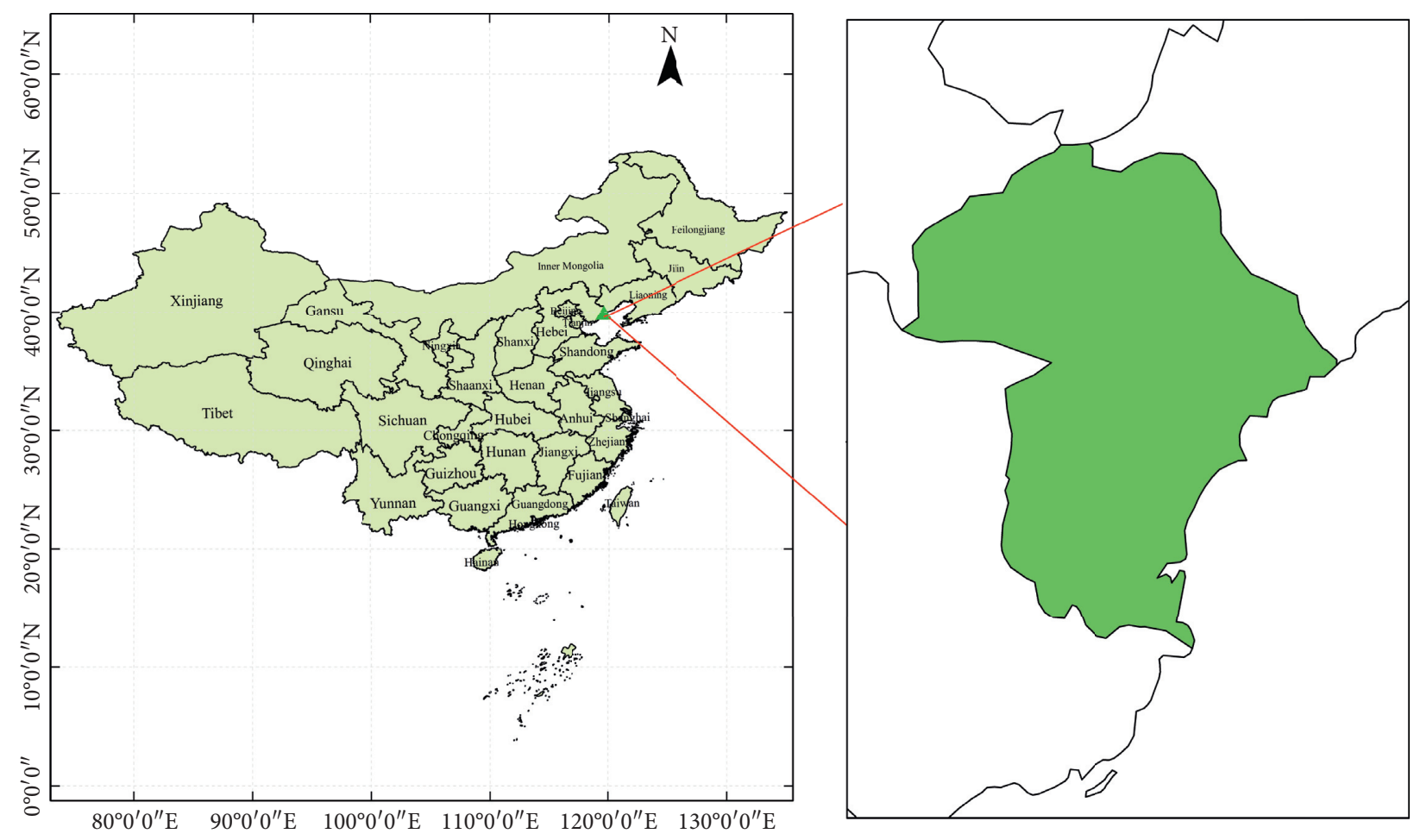

FIGURE 1: Locations of the Qinhuangdao city.

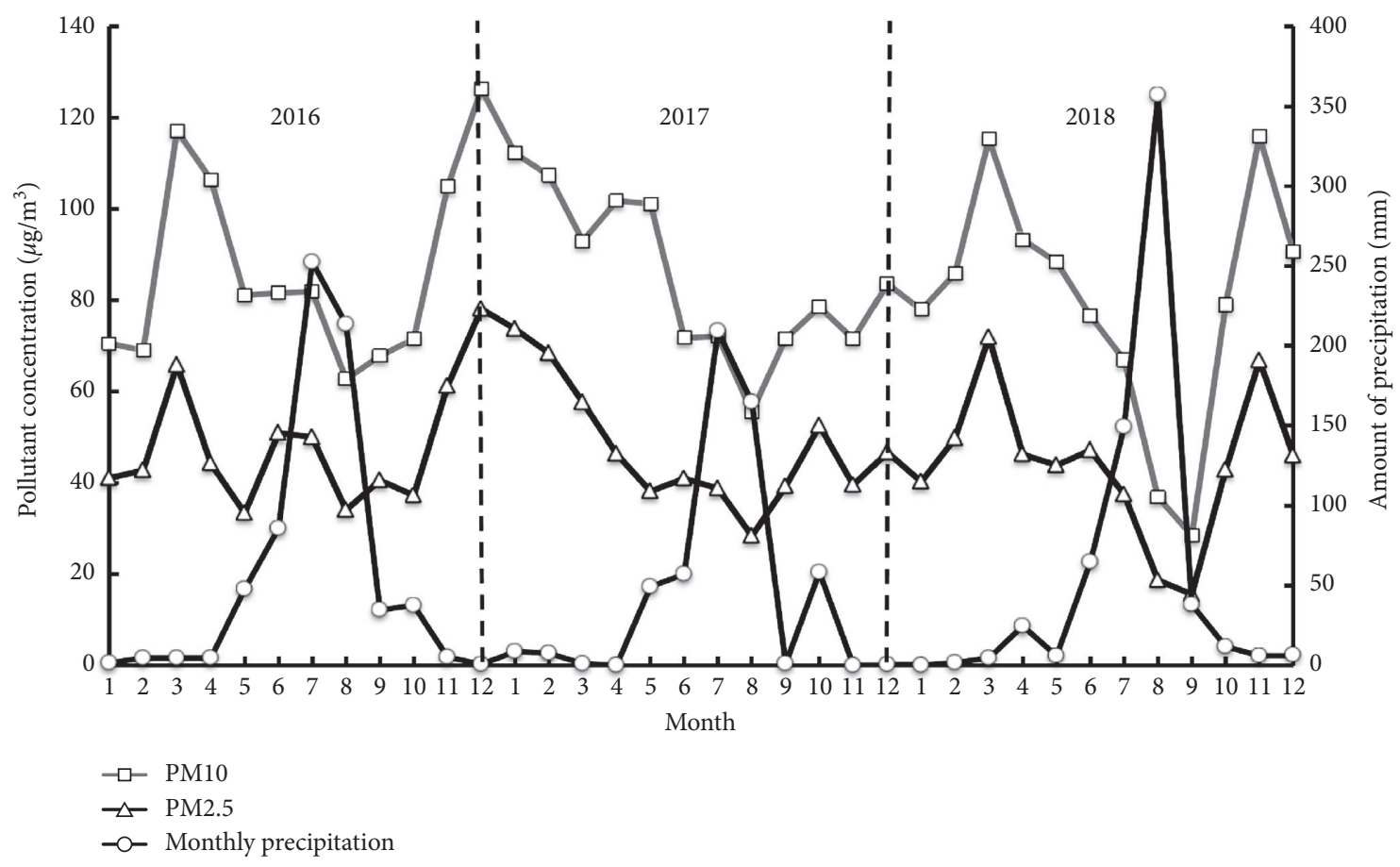

FIgURE 2: Monthly rainfall, PM2.5 and PM10 concentrations in Qinhuangdao from 2016 to 2018.

precipitation in July and August which is more than $200 \mathrm{~mm}$, while the precipitation in other months is less than $50 \mathrm{~mm}$; particularly from November to April of the following year, the monthly precipitation is below $10 \mathrm{~mm}$.

The mass concentrations of PM2.5 and PM10 have obvious seasonal distribution characteristics, with the lowest concentration in summer, the highest in winter, followed by spring and autumn. There is a significant negative correlation with precipitation. The higher the precipitation, the lower the concentration of PM2.5 PM10, which indicates that precipitation has a wet scavenging effect on PM2.5 and PM10. 


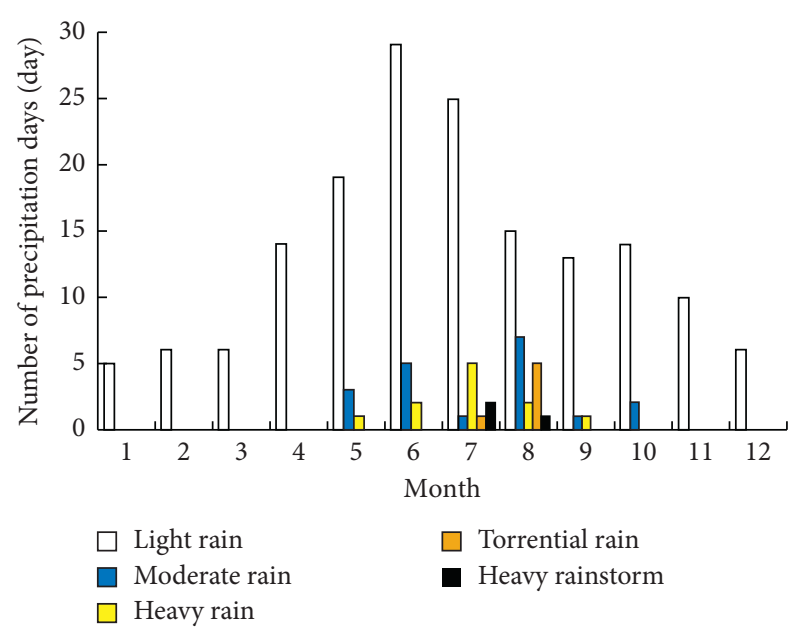

FIgURE 3: Histograms of the total of monthly averaged rainy days in Qinhuangdao for the period 2016-2018 by precipitation density: light (white hollow column), moderate (blue column), heavy rain (yellow column), torrential rain (orange column), and heavy rainstorm (black column).

The precipitation days of different orders of magnitude in each month in Qinhuangdao (Figure 3) also have obvious monthly variation characteristics, with relatively more precipitation days from May to October and less precipitation days from November to the next April. The changes in the number of precipitation days are not as significant as those in the number of precipitation months. Due to the heavy rain and precipitation of magnitude above the heavy rain from June to August, the monthly precipitation increases significantly. The monthly precipitation is the largest number of days of light rain magnitude, the percentage of light rain days is between $50 \%$ and $100 \%$, and the precipitation from November to the following year April is all of light rain magnitude. From the top part of the analysis we can know, from October to March of the following year, the mass concentrations of PM2.5 and PM10 have started to rise significantly; March and December are the two peak points of concentration. The corresponding precipitation in March and December is very small, and the number of precipitation days is also very small. From the perspective of precipitation alone, it may be related to the decrease of precipitation days, precipitation, or precipitation intensity.

3.2. Effects of Precipitation of Different Magnitudes on Pollutant Concentrations. In order to further study the effect of precipitation on PM2.5 and PM10 of different magnitudes, the distribution characteristics of mass concentrations of PM2.5 and PM10 corresponding to different precipitation levels in each month were statistically studied (Figure 4). Seasonally, the concentration of PM2.5 on rain-free days is the highest in winter, second in autumn and spring, and lowest in summer; PM10 concentration distribution is the highest in spring, followed by winter and lowest in summer. In addition to the impact of precipitation, in September the cold air begins to move frequently and the wind increases, resulting in a cleaner atmosphere, and after October the atmosphere is more and more stable, and the near-ground temperature is mostly inverted; meteorological conditions are not conducive to the vertical diffusion of pollutants and other factors lead to an increase of PM2.5 concentration. However, the concentration of PM10 is still high in April and May, mainly due to more and more frequent cold air activities in spring with relatively high wind; some floating dust will increase the concentration of PM10.

From the results, PM2.5 concentrations were higher on light rain days in February and October-December than on rain-free days. The concentration of PM2.5 on light rainy days in other months is lower than that on rain-free days. The concentration of PM10 is higher on light rain days in February and December than on rain-free days, while the concentration of PM10 on rainy days in other months is lower than that on rain-free days. In Qinhuangdao, moderate rainfall or above is concentrated from May to September, and the concentration of PM2.5 on moderate rain days from June to July and September and heavy rain days in May and September is higher than that on rain-free days. Therefore, light rain in spring and summer has an obvious scavenging effect on PM2.5, while light rain in late autumn and winter will increase the concentration of PM2.5. Light rain in spring, summer, and autumn has an obvious scavenging effect on PM10. From the above statistical results, it can be seen that light rain in winter will increase the concentration of pollutants, and the precipitation on PM10 concentration clearance effect is greater than that on PM2.5.

In order to further study the different effects of precipitation on PM2.5 and PM10, the ratio of PM2.5 and PM10 concentrations on rain-free days and rain days was analyzed (Figure 5). From the above analysis, it can be seen that precipitation on the decline of PM10 concentration is more obvious, and, from the statistics of Figure 4, it can be seen that the ratio of PM2.5 and PM10 concentration on rainy days each month is higher than that on rain-free days. The average ratio of PM2.5 and PM10 on rainy days and rain-free days was $62 \%$ and $54 \%$, respectively, and the proportion of rainy days increased by $8 \%$, which means that precipitation has a strong removal force of pollutants between 2.5 and 10 microns in dynamic diameter, which is consistent with the conclusions of studies of Yu Caixia.

\subsection{The Effect of Precipitation with Different Initial Pollutant} Concentrations on PM2.5 and PM10. In order to further study the effect of precipitation on pollutants, the 125 precipitation processes with precipitation duration of more than 2 hours in 2016-2018 were calculated, and the mass concentrations of PM2.5 (Figure 6) and PM10 (Figure 7) before and after precipitation were measured by different initial pollutant concentrations under different rainfall intensities. In the figure, the blue scattered points indicate the decrease of PM2.5 and PM10 concentration, while the red scattered points indicate the increase of PM2.5 and PM10. According to the distribution characteristics of the 5 scattered points in Figure 5, we divided the initial concentration of PM2.5 at $60 \mu \mathrm{g} / \mathrm{m}^{3}$ and the precipitation intensity of $5 \mathrm{~mm} / \mathrm{h}$ into three regional scopes for analysis. 


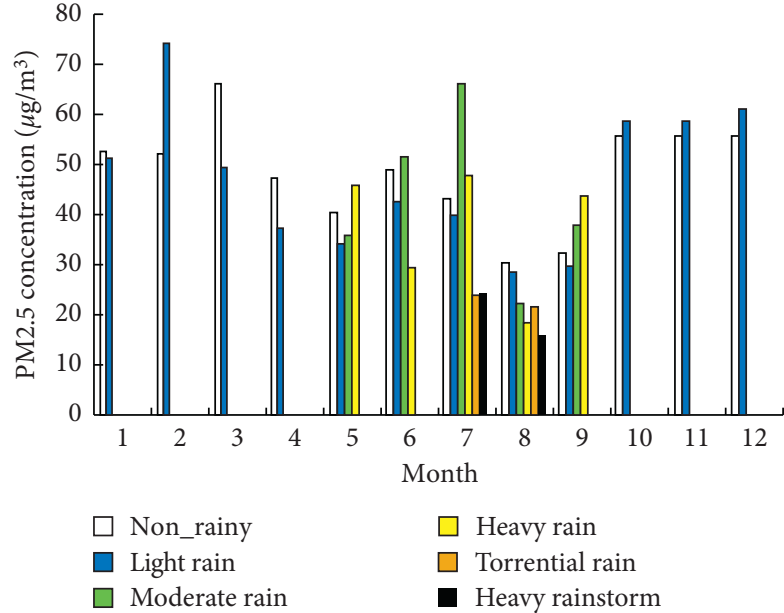

(a)

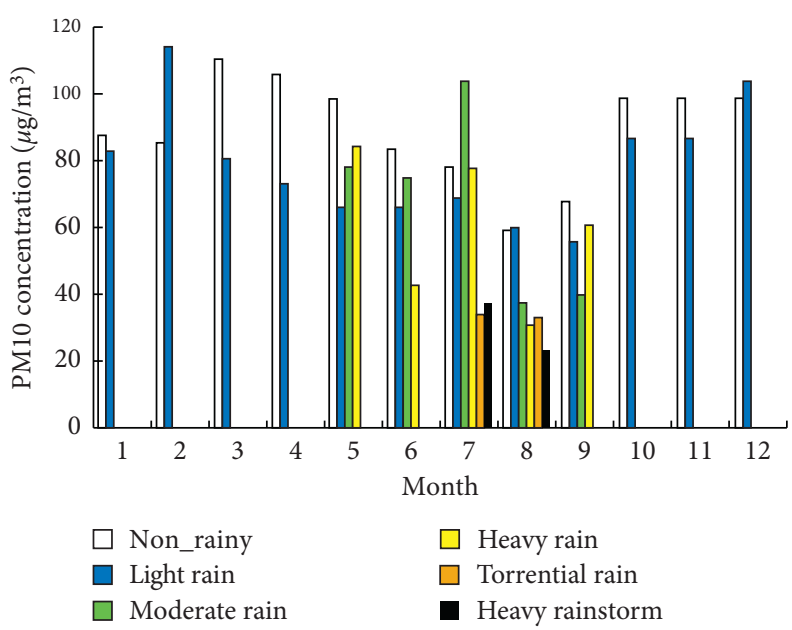

(b)

Figure 4: Monthly averaged PM2.5. (a) PM10. (b) Mass concentration between different precipitation intensities at Qinhuangdao from 2016 to 2018: nonrainy (white hollow column), light rain (blue column), moderate rain (green column), heavy rain (yellow column), torrential rain (orange column), and heavy rainstorm (black column).

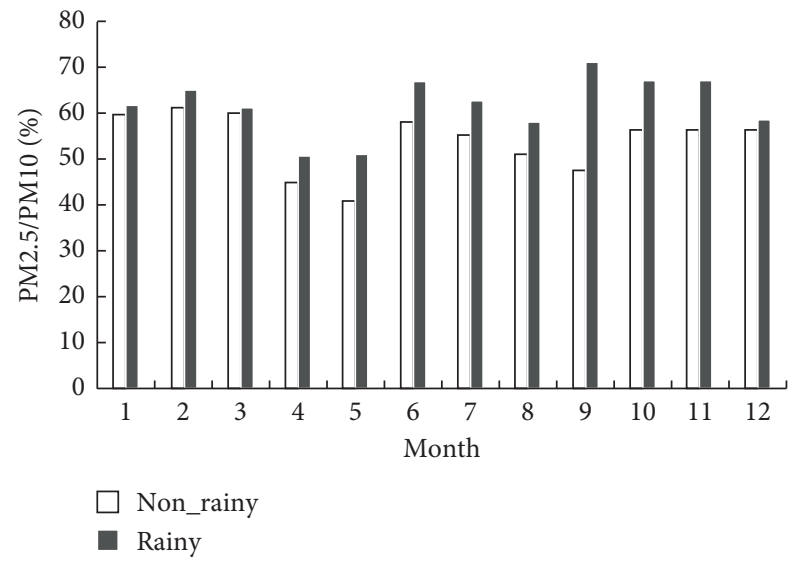

FIGURE 5: Mass concentration of PM2.5 /PM10 on rainy days and nonrainy days at Hefei.

As can be seen from Figure 5, we have the following. Scope 1: when the initial mass concentration of PM2.5 is more than $60 \mu \mathrm{g} / \mathrm{m}^{3}$ and the precipitation intensity is less than $5 \mathrm{~mm} / \mathrm{h}$, the precipitation has a clear effect on PM2.5, indicating that when the air quality is relatively poor, the precipitation will have a clear effect on pollutants. Scope 2: when the initial mass concentration of PM2.5 is less than $60 \mu \mathrm{g} / \mathrm{m}^{3}$ and the precipitation intensity is less than $5 \mathrm{~mm} / \mathrm{h}$, there are 64 cases. In 25 cases, the concentration of PM2.5 increases, accounting for $39.1 \%$. Scope 3: when the initial mass concentration of PM2.5 is less than $60 \mu \mathrm{g} / \mathrm{m}^{3}$ and the precipitation intensity is more than $5 \mathrm{~mm} / \mathrm{h}$, the precipitation intensity in this range is high. The higher the initial concentration of PM2.5, the greater the amount of removal of PM2.5.

In Scope 2, the precipitation intensity is less than $5 \mathrm{~mm} / \mathrm{h}$ and PM2.5 initial concentration is less than $60 \mu \mathrm{g} / \mathrm{m}^{3}$, after the rain PM2.5 concentration has increased or decreased; in order to further explain the effect of precipitation on PM2.5 concentration under this condition, the precipitation intensity is divided into less than $1 \mathrm{~mm} / \mathrm{h}$ and $1-5 \mathrm{~mm} / \mathrm{h}$, the concentration of PM2.5 before precipitation is less than $35 \mu \mathrm{g} / \mathrm{m}^{3}$ and $35-60 \mu \mathrm{g} / \mathrm{m}^{3}$, and the precipitation duration is further analyzed (Figure 8).

When the precipitation intensity is less than $1 \mathrm{~mm} / \mathrm{h}$, PM2.5 concentration increases in both initial concentration and precipitation duration in the two ranges, indicating that when the precipitation intensity is less than $1 \mathrm{~mm} / \mathrm{h}, \mathrm{PM} 2.5$ initial concentration is less than $60 \mu \mathrm{g} / \mathrm{m}^{3}$ and the effect of precipitation on PM2.5 is highly uncertain. This should be due to the weak precipitation; precipitation for the pollution of the flushing effect is not obvious, but for the air aerosols to provide humidity conditions, conducive to aerosol moisture absorption growth, thereby increasing the concentration of PM2.5. When the precipitation intensity is between 1 and $5 \mathrm{~mm} / \mathrm{h}$, the initial concentration of PM2.5 is less than $35 \mu \mathrm{g} / \mathrm{m}^{3}, \mathrm{pm} 2.5$ concentration is mostly reduced after precipitation, and some of the concentrations increase or remain unchanged; when the precipitation intensity is between 1 and $5 \mathrm{~mm} / \mathrm{h}$, the initial concentration of PM2.5 is greater than $35 \mu \mathrm{g} / \mathrm{m}^{3}$, and the precipitation lasts for more than 3 hours; the PM2.5 concentration significantly decreases after precipitation. This shows that when the PM2.5 concentration in Qinhuangdao is less than $35 \mu \mathrm{g} / \mathrm{m}^{3}$ (i.e., the air quality is excellent), the precipitation intensity is less than $5 \mathrm{~mm} / \mathrm{h}$, the PM2.5 concentration is less than $60 \mu \mathrm{g} / \mathrm{m}^{3}$, the precipitation intensity is less than $1 \mathrm{~mm} / \mathrm{h}$, and the PM2.5 concentration often increases after the rain.

According to the distribution characteristics of scattered points in Figure 7, we divided the initial concentration of PM10 $100 \mu \mathrm{g} / \mathrm{m}^{3}$ and precipitation intensity $(5 \mathrm{~mm} / \mathrm{h})$ into three ranges for analysis. As can be seen from Figure 7, we have the following. Scope 1: When the initial PM10 mass concentration is more than $100 \mu \mathrm{g} / \mathrm{m}^{3}$ and the precipitation intensity is less than $5 \mathrm{~mm} / \mathrm{h}$, the precipitation has an obvious scavenging effect on PM10, indicating that when the 


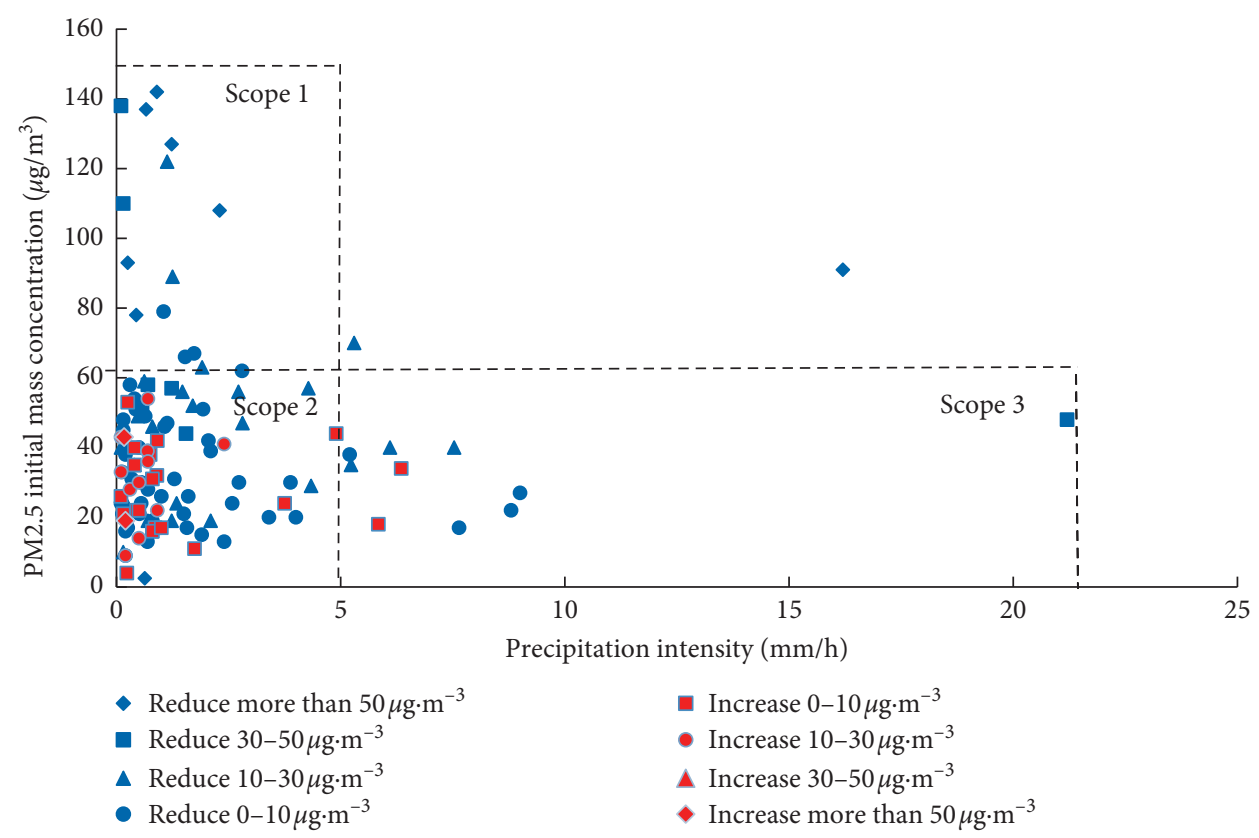

FIGURE 6: The relationship between PM2.5 mass concentration and precipitation intensity and initial mass concentration.

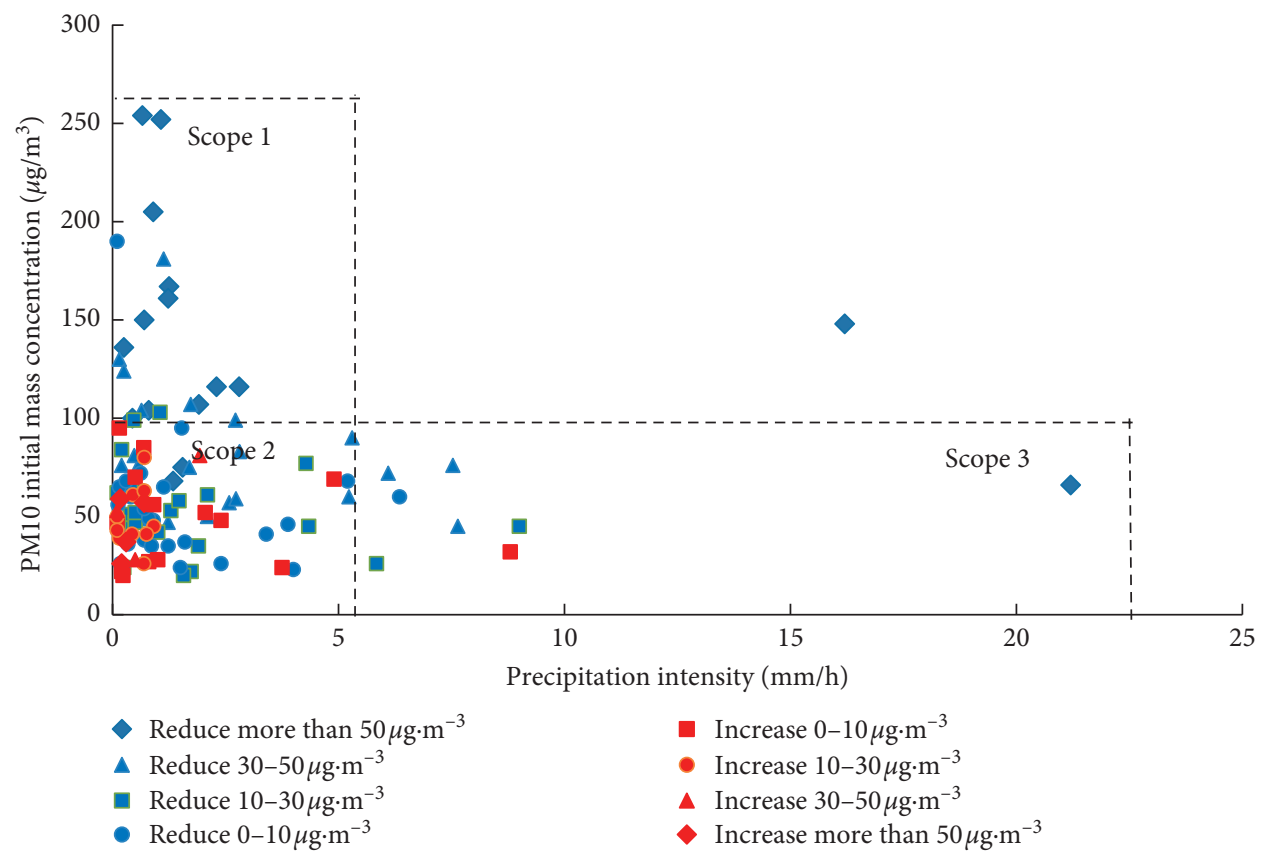

FIGURE 7: The relationship between PM10 mass concentration and precipitation intensity and initial mass concentration.

air quality is relatively poor, the precipitation will have an obvious scavenging effect on pollutants. Scope 2: when the initial PM10 mass concentration is less than $100 \mu \mathrm{g} / \mathrm{m}^{3}$ and the precipitation intensity is less than $5 \mathrm{~mm} / \mathrm{h}$, there are 96 cases in total. Among them, the PM10 concentration increases after precipitation in 38 cases, accounting for $39.6 \%$. This indicates that when the initial concentration of PM10 is low, that is, in fine weather, weak precipitation (less than $2 \mathrm{~mm} / \mathrm{h}$ ) will sometimes increase the concentration of PM10. Scope 3: when the initial PM10 mass concentration is less than $100 \mu \mathrm{g} / \mathrm{m}^{3}$ and the precipitation intensity is greater than $5 \mathrm{~mm} / \mathrm{h}$, the precipitation intensity in this range is high. The higher the initial PM10 concentration is, the greater the clearance amount of precipitation to PM10 is.

The above results show that the scavenging effect of precipitation on PM10 has a great relationship with the initial concentration of PM10. To further study the relationship between the two (Figure 7), the initial concentration of PM10 is divided into four ranges: $0-50 \mu \mathrm{g} / \mathrm{m}^{3}$, $50-100 \mu \mathrm{g} / \mathrm{m}^{3}, 100-150 \mu \mathrm{g} / \mathrm{m}^{3}$, and $150-500 \mu \mathrm{g} / \mathrm{m}^{3}$, studying the relationship between precipitation and the average decrease of PM10 concentration (Figure 9). When the initial 


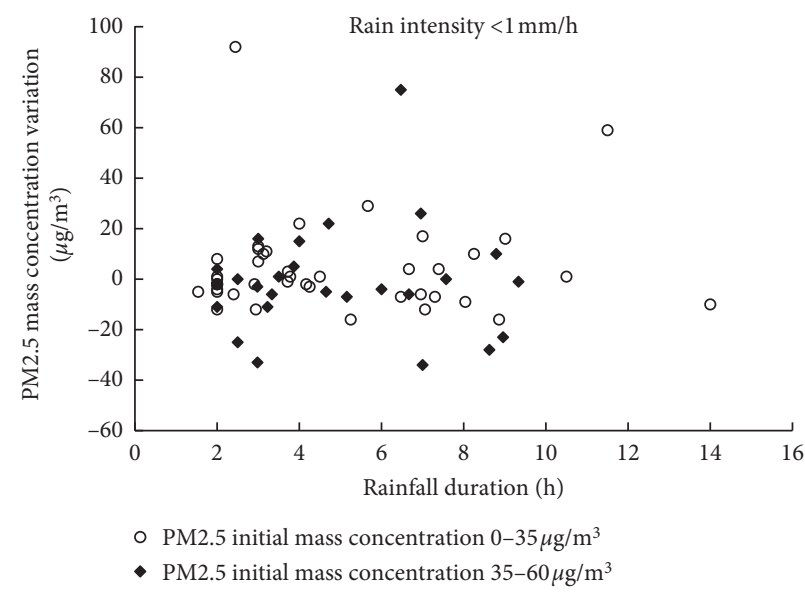

(a)

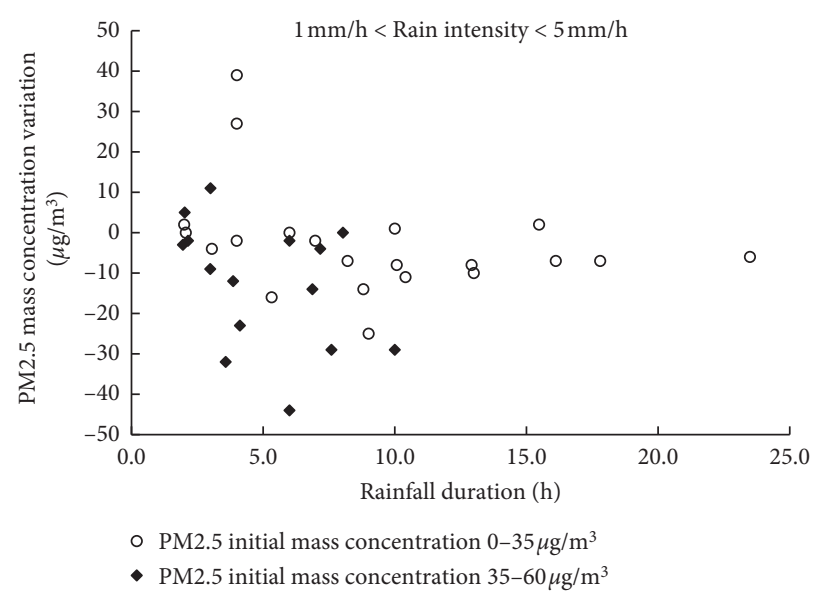

(b)

Figure 8: The relationship between mass concentration variation of PM2.5 and rainfall duration.

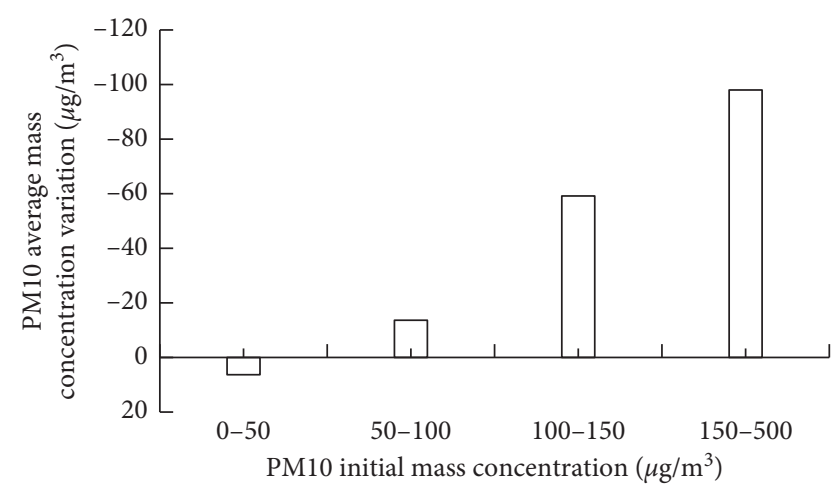

FIGURE 9: Relationship between the clearing effect of precipitation on PM10 and the initial concentration of PM10.

concentration of PM10 is between 50 and $100 \mu \mathrm{g} / \mathrm{m}^{3}$, the concentration of PM10 after precipitation decreases by $13.6 \mu \mathrm{g} / \mathrm{m}^{3}$ on average. When the initial concentration is between 100 and $150 \mu \mathrm{g} / \mathrm{m}^{3}$, the concentration of PM10 after precipitation will decrease by $59.2 \mu \mathrm{g} / \mathrm{m}^{3}$ on average. When the initial concentration is between $150-500 \mu \mathrm{g} / \mathrm{m}^{3}$, the concentration of PM10 after precipitation will decrease by $98.0 \mu \mathrm{g} / \mathrm{m}^{3}$ on average. When the initial concentration is below $50 \mu \mathrm{g} / \mathrm{m}^{3}$, the concentration of PM10 after precipitation will increase by $6.3 \mu \mathrm{g} / \mathrm{m}^{3}$ on average. This indicates that the higher the initial concentration of PM10, the more obvious the scavenging effect of precipitation on PM10. And when the initial concentration of PM10 is less than $50 \mu \mathrm{g} / \mathrm{m}^{3}$ (air quality is excellent), the scavenging effect of precipitation with different intensity and time length on PM10 is still very uncertain.

In order to further study the scavenging effect of precipitation on PM10 when the initial concentration of PM10 is low, taking $100 \mu \mathrm{g} / \mathrm{m}^{3}$ as the boundary, the relationship between the change of PM10 concentration and the duration of precipitation before and after the rain with different rain intensity and initial concentration decrease was analyzed (Figure 10). When the initial concentration is less than $100 \mu \mathrm{g} / \mathrm{m}^{3}$, PM10 concentration of precipitation with different rainfall intensity and duration increases to a certain extent, and the concentration will rebound the most when the rain intensity is less than $1 \mathrm{~mm} / \mathrm{h}$. When the initial concentration of PM10 is higher than $100 \mu \mathrm{g} / \mathrm{m}^{3}$, the precipitation with different rain intensity and time length will reduce the concentration of PM10 to different degrees, and the higher the initial concentration of PM10 is, the greater the precipitation clearance will be.

3.4. Relationship between Pollutants Distribution and Wind Direction and Speed. In order to study the relationship between pollutant distribution and wind direction and speed, this paper divides wind direction into 8 directions, respectively, north wind $\mathrm{N}\left(337.5^{\circ}-22.5^{\circ}\right)$, northeast wind $\mathrm{NE}\left(22.5^{\circ}-67.5^{\circ}\right)$, east wind $\mathrm{E}\left(67.5^{\circ}-112.5^{\circ}\right)$, southeast wind SE $\left(112.5^{\circ}-157.5^{\circ}\right)$, south wind $S\left(157.5^{\circ}-202.5^{\circ}\right)$, southwest wind SW $\left(202.5^{\circ}-247.5^{\circ}\right)$, west wind $\mathrm{W}\left(247.5^{\circ}-292.5^{\circ}\right)$, and northwest wind NW $\left(292.5^{\circ}-337.5^{\circ}\right)$, and the velocity of a stationary wind is less than $0.4 \mathrm{~m} / \mathrm{s}$. The dominant wind direction in each season in Qinhuangdao is not the same, so the probability distribution of wind direction and speed in the four seasons and the distribution of pollutants are, respectively, calculated.

3.4.1. Distribution of Wind Direction and Speed and Relationship between Pollutants and Wind Direction and Speed of Qinhuangdao in Spring. According to the statistical results of wind direction and speed probability distribution in spring (April-May) in Qinhuangdao from 2016 to 2019, as can be seen (Figure 11), the dominant wind direction in spring is southeast wind (28.3\%), east wind (19.26\%), and northeast wind (13.66\%). As can be seen from Figure 10(b), pollution weather in spring has two peaks in the wind direction, ranging from $45^{\circ}$ to $125^{\circ}$ and $180^{\circ}$ to $270^{\circ}$. That is to say, the pollution weather in spring mainly occurs between the northeast wind and the east wind and between the southwest wind and the west wind, and the pollution weather mostly occurs in the period below the breeze force 3 wind (wind speed is less than or equal to $5.4 \mathrm{~m} / \mathrm{s}$ ); moderate 


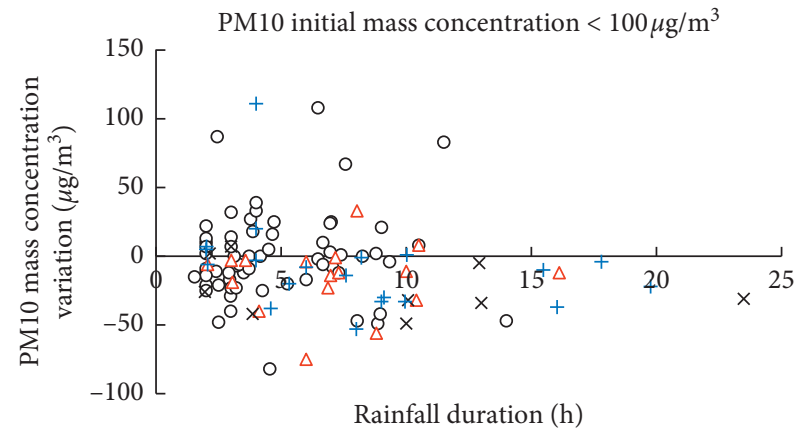
- Precipitation intensity $<1$
$\triangle$ Precipitation intensity $1-2$

(a)

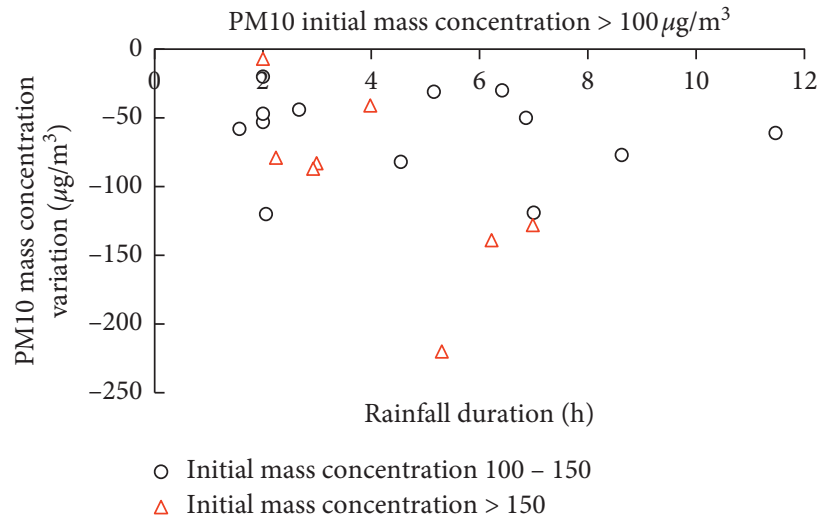

(b)

FIgURE 10: Relationship between the change of PM10 concentration and the duration of precipitation.

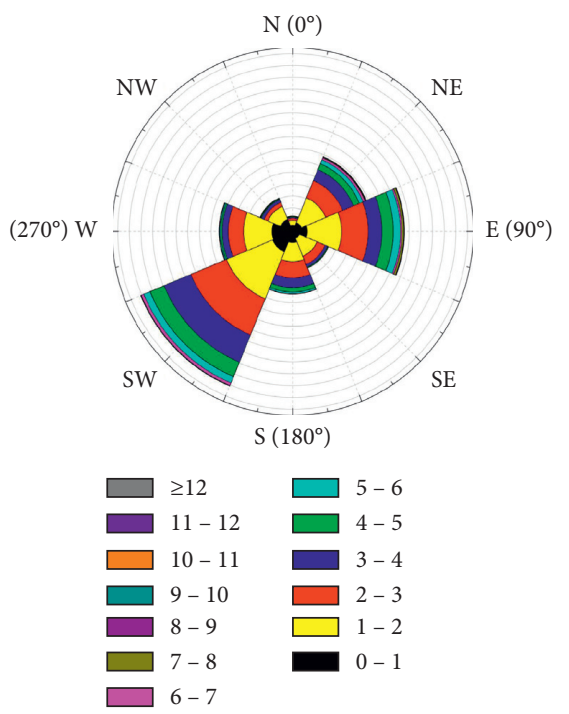

(a)

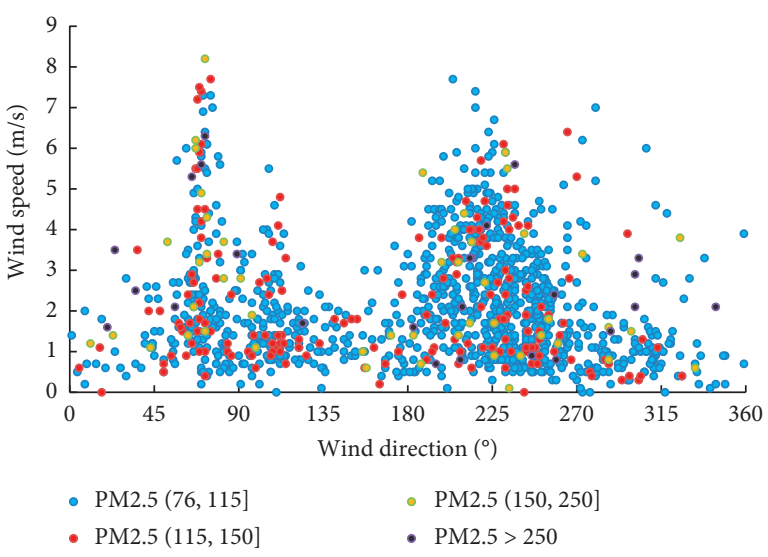

(b)

FIGURE 11: The wind rose diagram at Qinhuangdao. (a) The relationship between PM2.5, (b) mass concentration, and wind speed and wind direction in spring.

or above pollution is rare when wind speed is higher than level 3. In spring, there are not many days with severe pollution due to PM2.5 concentration, and severe pollution mainly occurs under the meteorological conditions of southwest wind or west wind. PM10 concentration is not high in spring, and the pollution weather is basically mild pollution and below (figure not shown).

3.4.2. Wind Direction and Speed Distribution and the Relationship between Pollutants and Wind Direction and Speed of Qinhuangdao in Summer. According to the statistical results of probability distribution of wind speed in summer (June-August) in Qinhuangdao area (Figure 12), the dominant wind direction in summer is the same as that in spring, which is southeast wind (24.92\%), east wind
(16.79\%), and northeast wind (14.39\%). From Figure 12(b), it can be seen that, in summer, the moderate and above pollution weather is less and there is no severe pollution weather. In summer, the pollution weather mainly occurs in the northeast wind, southeast wind, and southwest to west wind weather conditions; the most is the southwest to west wind weather conditions, and the pollution weather also mostly occurs in the period below the breeze level 3 wind (the wind speed is less than or equal to $5.4 \mathrm{~m} / \mathrm{s}$ ).

3.4.3. Wind Direction and Speed Distribution and Relationship between Pollutants and Wind Direction and Speed of Qinhuangdao in Autumn. According to the statistical results of wind speed probability distribution in autumn (September 1-November 14) (Figure 13(a)), the dominant 


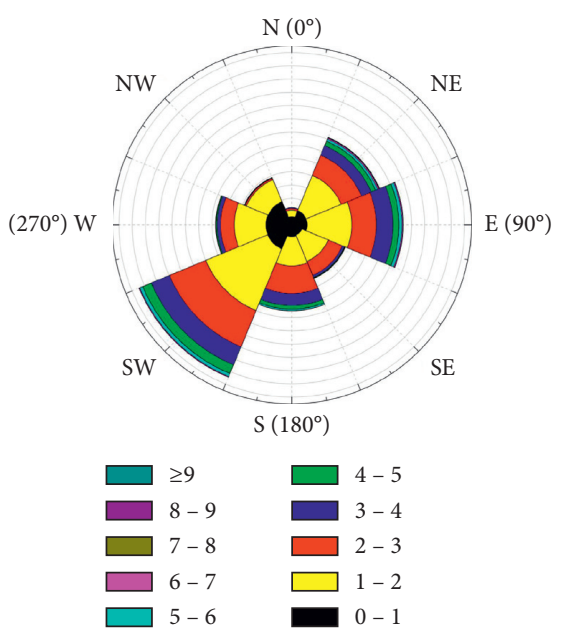

(a)

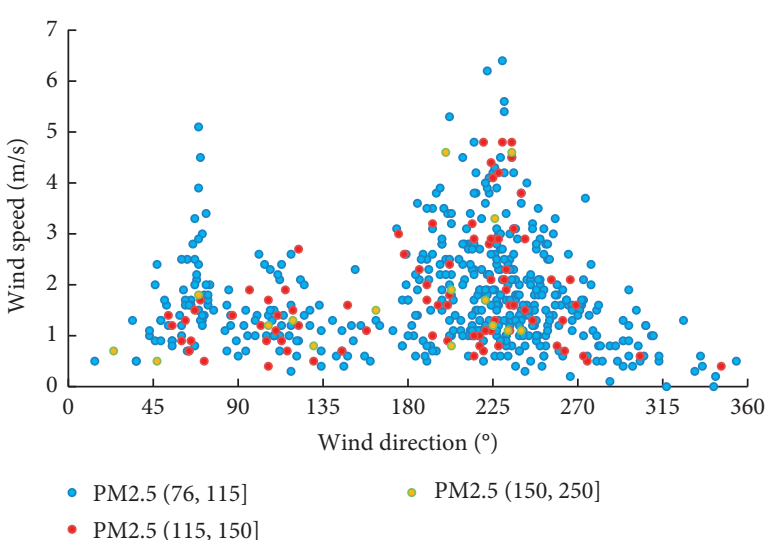

(b)

FIGURE 12: The wind rose diagram at Qinhuangdao. (a) The relationship between PM2.5, (b) mass concentration, and wind speed and wind direction in summer.

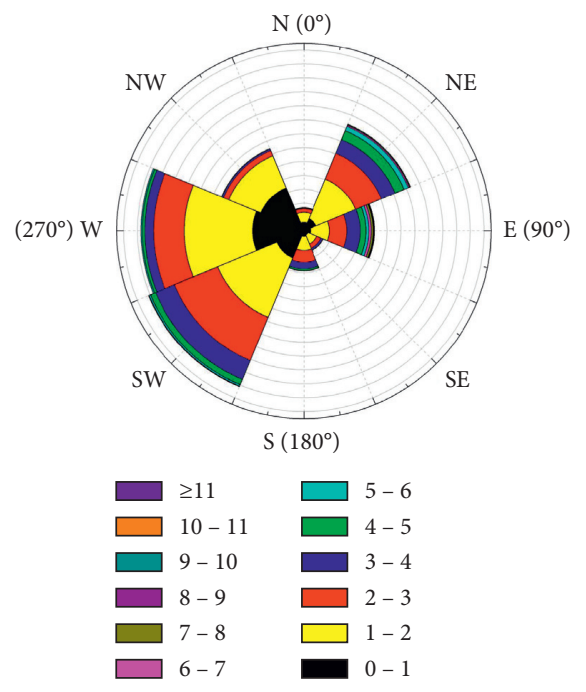

(a)

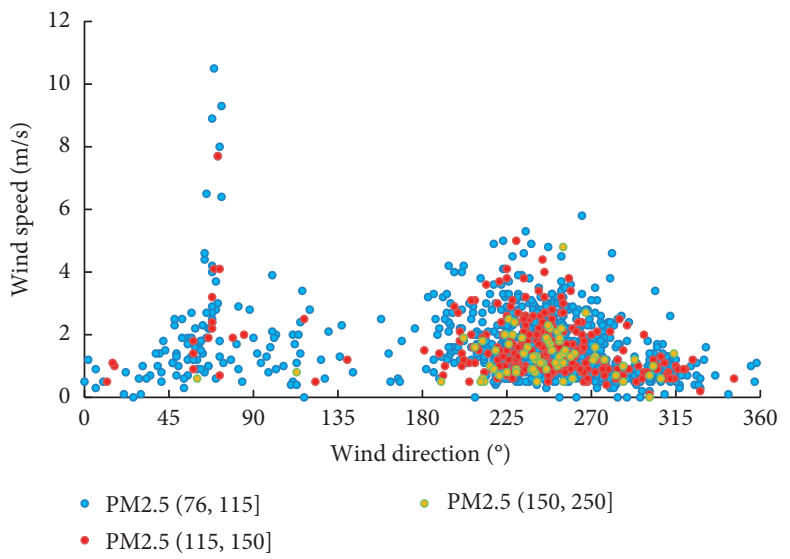

(b)

FIGURE 13: The wind rose diagram at Qinhuangdao. (a) The relationship between PM2.5, (b) mass concentration, and wind speed and wind direction in autumn.

wind direction in autumn is southwest wind (24.29\%), west wind $(23.62 \%)$, and northeast wind (16.65\%). Figure 13(b) shows that the pollution weather in autumn is mainly concentrated in the range of $200^{\circ}-315^{\circ}$; that is, the pollution weather in autumn mainly occurs between southwest and west winds, and the pollution weather mostly occurs in the period when the wind speed is less than or equal to $4 \mathrm{~m} / \mathrm{s}$; when the wind speed is more than $4 \mathrm{~m} / \mathrm{s}$, moderate or above pollution weather seldom occurs. The heavy pollution weather of PM2.5 concentration in autumn is more than that in spring and summer, mainly under southwest or west wind meteorological conditions. PM10 concentration is not high in autumn, and the pollution weather is basically light pollution or below, and there is no pollution with PM10 concentration above medium level (figure not shown).
3.4.4. Wind Direction and Speed Distribution and the Relationship between Pollutants and Wind Direction and Speed of Qinhuangdao in Winter. The statistical results of wind speed probability distribution in winter (November 15 to March of the next year) are shown in Figure 14(a). It can be seen that winter is the most polluted season in the four seasons. The main wind direction in winter is west $(21.56 \%)$, southwest (19.48\%), and east wind (17.29\%). Figure 14(b) shows that $53 \%$ of the PM2.5 concentration pollution weather is of moderate or above pollution level, and the wind direction of the pollution weather in winter is concentrated in the range of $45^{\circ}-125^{\circ}$ and $200^{\circ}-315^{\circ}$; that is, the pollution weather in winter mainly occurs between the northeast wind and the easterly wind and between the southwest and the westerly wind. The polluted weather is also mostly in the 


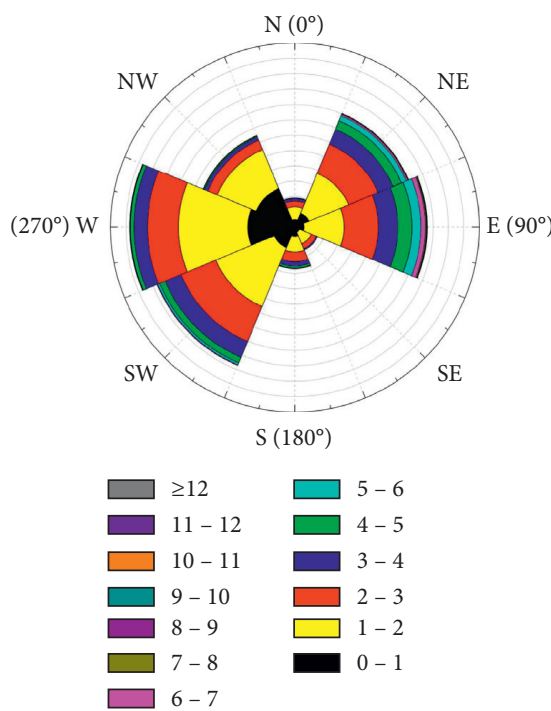

(a)

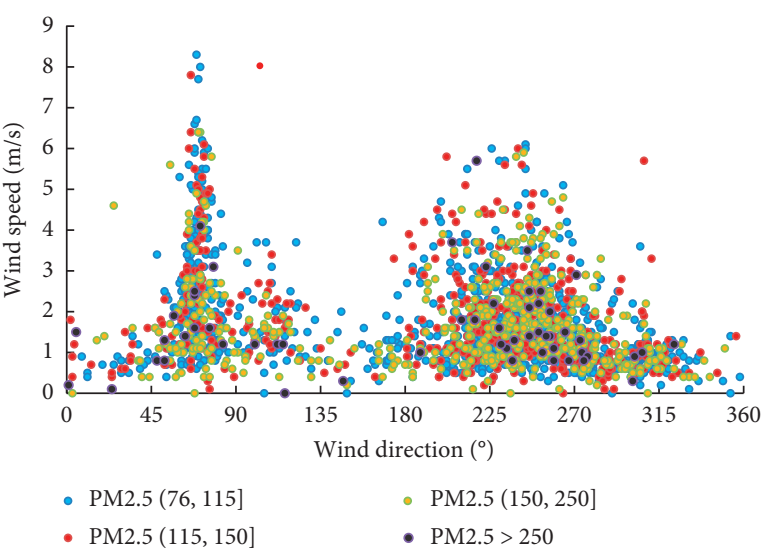

(b)

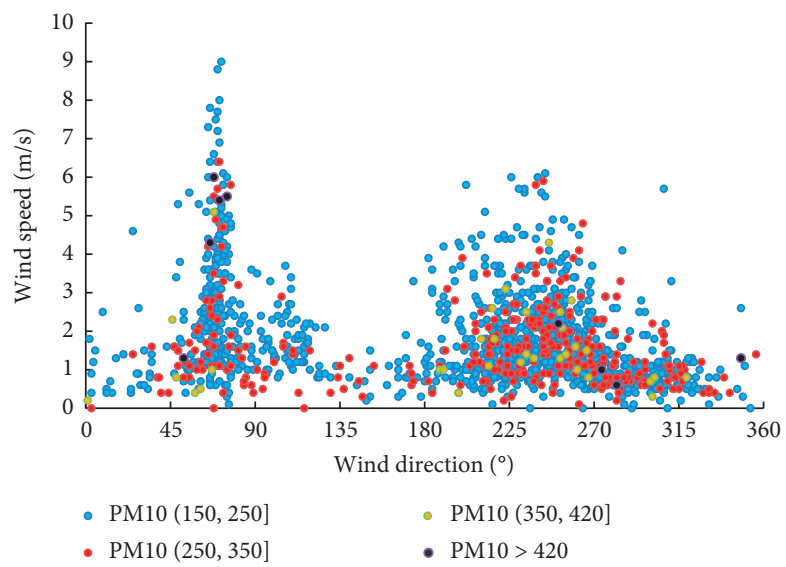

(c)

FIGURE 14: The wind rose diagram at Qinhuangdao. (a) The relationship between PM2.5, (b) PM10, (c) mass concentration, and wind speed and wind direction in winter.

period below the breeze level 3 wind. Moderate or above pollution is rare when the wind speed is more than $5 \mathrm{~m} / \mathrm{s}$. In winter, PM2.5 concentration is more serious in polluted weather, mainly under the meteorological conditions of northeast wind, southwest wind, and west wind. Figure 14(c) shows that the concentration of PM10 in winter is also the highest in the four seasons, and the distribution pattern is similar to that of PM2.5.

From the above analysis, it can be seen that the moderate and above pollution weather in Qinhuangdao mainly occurs under the meteorological conditions of northeast wind, southwest wind, and westerly wind. The more westerly the wind, the more serious the pollution. The pollution levels in the four seasons from heavy to light are sorted for the winter $>$ autumn $>$ spring $>$ summer; precipitation factors are aside, from the perspective of the wind direction; it is mainly due to the fact that the wind direction in Qinhuangdao area is towards the west, which largely affects the concentration of pollutants. In winter, during the heating period, man-made emission sources increase, precipitation decreases, and the dominant wind direction is towards the west, so the pollutants are transported from the west and gather. The wind direction in autumn is mainly southwest and west, and the concentration should be followed by the wind direction.

3.4.5. Removal of PM2.5 and PM10 by Different Wind Speeds. According to the above analysis, we divide the wind direction into four ranges: $22.5^{\circ}-112.5^{\circ}, 112.5^{\circ}-202.5^{\circ}$, $202.5^{\circ}-292.5^{\circ}$, and $292.5^{\circ}-22.5^{\circ}$ and studied the scavenging effect of different wind speeds on PM2.5 and PM10 under the four wind directions. As can be seen from Figure 15(a), in Qinhuangdao, the concentration of PM2.5 is the highest under west and southwest wind in all wind speed conditions in the four wind direction ranges. Moreover, when the wind speed increases to $2-3 \mathrm{~m} / \mathrm{s}$, the concentration of PM2.5 in all three wind directions except west wind and southwest wind significantly decreases. Among them, the north wind and northwest wind have the most obvious scavenging effect, 


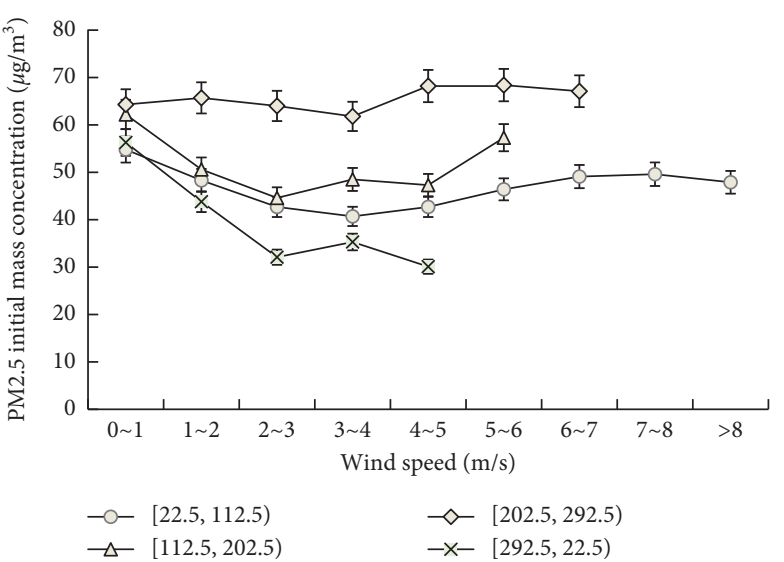

(a)

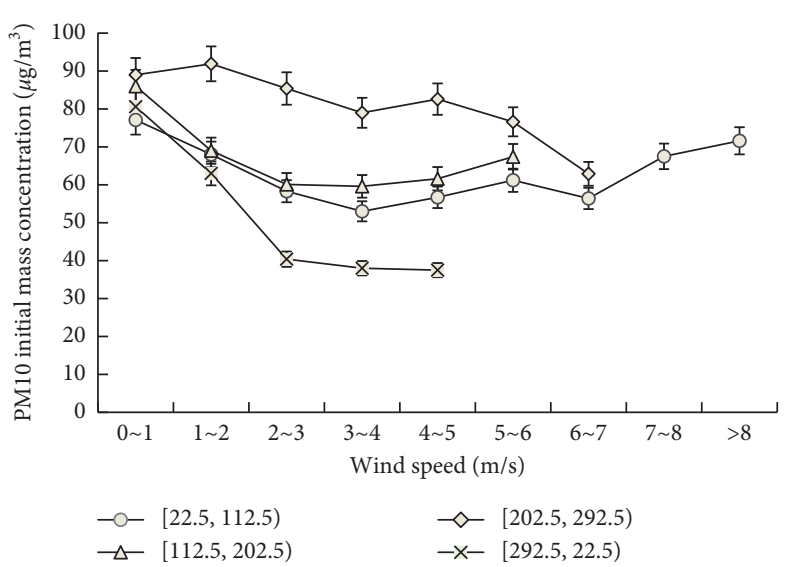

(b)

Figure 15: PM2.5. (a) PM10. (b) Mass concentration variation under different wind speed and wind direction.

while the west wind and southwest wind have the worst scavenging effect. Moreover, with the increase of wind speed, PM2.5 concentration increases.

Figure 15(b) shows the relationship between PM10 concentration and wind speed. The four wind direction ranges all continue to decrease as wind speed increases to $4 \mathrm{~m} / \mathrm{s}$. Northwest wind and north wind have the most obvious effect on the removal of PM10 concentration. With the wind speed greater than $4 \mathrm{~m} / \mathrm{s}$, PM10 concentration under the conditions of south wind southeast wind and east wind northeast begins to rise, which should be due to the increase of wind speed, causing dust on the ground, aggravating PM10 pollution.

\section{Conclusion}

(1) Precipitation has a certain wet scavenging effect on PM2.5 and PM10, and the scavenging effect of precipitation on PM10 is greater than that of PM2.5. From the point of view of precipitation magnitude, the precipitation above the moderate rain in Qinhuangdao area is concentrated from May to September, while the light rain in winter often increases the concentration of pollutants.

(2) The change of PM2.5 before and after precipitation is related to the initial concentration of PM2.5 before precipitation, precipitation intensity, and precipitation duration. When the initial concentration of PM2.5 is less than $60 \mu \mathrm{g} / \mathrm{m}^{3}$ and the precipitation intensity is greater than $5 \mathrm{~mm} / \mathrm{h}$, the higher the initial concentration of PM2.5 is, the greater the removal of PM2.5 by precipitation will be. When the initial PM2.5 concentration is more than $60 \mu \mathrm{g} / \mathrm{m}^{3}$ and the precipitation intensity is less than $5 \mathrm{~mm} / \mathrm{h}$, the PM2.5 concentration decreases after precipitation. In other words, when the air quality is relatively poor, the precipitation will remove pollutants; that is, when the air quality is relatively poor, the precipitation will play a role in scavenging pollutants.

(3) The scavenging effect of precipitation on PM10 is closely related to the initial concentration of PM10 before precipitation. When the initial concentration is lower than $100 \mu \mathrm{g} / \mathrm{m}^{3}$, PM10 concentration increases to a certain extent under different rain intensity and precipitation duration, and the concentration rebounds the most when the rain intensity is less than $1 \mathrm{~mm} / \mathrm{h}$; however, when the initial concentration of PM10 is higher than $100 \mu \mathrm{g} / \mathrm{m}^{3}$, precipitation with different rainfall intensity and time makes the PM10 concentration decrease in varying degrees, and the higher the initial concentration of PM10 is, the greater the clearing amount of precipitation will be.

(4) The moderate and above pollution weather in Qinhuangdao mainly occurs under the meteorological conditions of northeast wind, southwest wind, and westerly wind. The more westerly the wind is, the more serious the pollution will be, and, with the increase of wind speed, PM2.5 concentration will increase. North wind and northwest wind have the most obvious scavenging effect on PM2.5 and Pm10. In addition to west and southwest winds, when the wind speed increases to $2 \mathrm{~m} / \mathrm{s}$, PM2.5 and PM10 concentrations can be reduced. However, when the wind speed is more than $4 \mathrm{~m} / \mathrm{s}$, the PM10 concentration under the south, southeast, east, and northeast wind rebounds. As the wind speed increases, dust is generated on the ground and PM10 pollution is aggravated.

\section{Data Availability}

The meteorological and environmental data used to support the findings of this study have not been made available because these data can be downloaded and viewed on the internal network of Hebei Meteorological Bureau; the external network is not supported.

\section{Conflicts of Interest}

The authors declare that they have no conflicts of interest. 


\section{Acknowledgments}

This study was supported by the National Natural Science Foundation of China (no. 41375038) and Youth Fund of Hebei Meteorological Bureau (no. 17ky25).

\section{References}

[1] D. Huang, J. Xu, and S. Zhang, "Valuing the health risks of particulate air pollution in the Pearl River Delta, China," Environmental Science \& Policy, vol. 15, no. 1, pp. 38-47, 2012.

[2] L. Wang, N. Zhang, Z. Liu et al., "The influence of climate factors, meteorological conditions, and boundary-layer structure on severehaze pollution in the Beijing-Tianjin-Hebei region during January2013," Advances in Meteorology, vol. 2014, no. 7, 14 pages, 2015.

[3] Q. B. Du, X. Y. Wu, S. F. Zheng et al., "Effects of meteorologyical conditions on PM2.5 pollution in Shantou and the PM2.5 prediction," Journal of Meteorology and Environment, vol. 35 , no. 5 , pp. 70-77, 2019.

[4] M. M. Grazia, V. Stefano, V. Gianluigi et al., "Characteristics of PM10 and PM2.5 particulate matter in the ambient air of Milan," Atmospheric Environment, vol. 35, no. 27, pp. 46394650, 2001.

[5] F. Duan, K. He, Y. Ma et al., "Concentration and chemical characteristics of PM2.5 in Beijing, China: 2001-2002," Science of The Total Environment, vol. 355, no. 1-3, pp. 264-275, 2006.

[6] L. Li, W. Wang, J. Feng et al., "Composition, source, mass closure of PM2.5 aerosols for four forests in eastern China," Journal of Environmental Sciences, vol. 22, no. 3, pp. 405-412, 2010.

[7] X. J. Zhao, P. S. Zhao, J. Xu et al., "Analysis of a winter regional haze event and its formation mechanism in the North China Plain," Atmospheric Chemistry and Physics Discussions, vol. 13, no. 1, pp. 903-933, 2013.

[8] B. Bowe, Y. Xie, Y. Yan et al., "Burden of cause-specific mortality associated with PM2.5 air pollution in the United States," JAMA Network Open, vol. 2, no. 11, Article ID e1915834, 2019.

[9] P. Yin, J. Guo, L. Wang et al., "Higher risk of cardiovascular disease associated with smaller size-fractioned particulate matter," Environmental Science \& Technology Letters, vol. 7, no. 2, pp. 95-101, 2020.

[10] U. Lohmann and J. Feichter, "Can the direct and semi-direct aerosol effect compete with the indirect effect on a global scale?" Geophysical Research Letters, vol. 28, no. 1, pp. 159$161,2001$.

[11] S. Twomey, "The influence of pollution on the shortwave albedo of clouds," Journal of the Atmospheric Sciences, vol. 34, no. 7, pp. 1149-1154, 1977.

[12] T. Chen, J. Guo, Z. Li et al., "A CloudSat perspective on the cloud climatology and its association with aerosol perturbations in the vertical over eastern China," Journal of the Atmospheric Sciences, vol. 73, no. 9, pp. 3599-3616, 2016.

[13] J. Guo, M. Deng, S. S. Lee et al., "Delaying precipitation and lightning by air pollution over the Pearl River Delta. Part I: observational analyses," Journal of Geophysical Research: Atmospheres, vol. 121, no. 11, pp. 6472-6488, 2016.

[14] J. Guo, T. Su, D. Chen et al., "Declining summertime localscale precipitation frequency over China and the United States, 1981-2012: the disparate roles of aerosols," Geophysical Research Letters, vol. 46, no. 22, pp. 13281-13289, 2019.

[15] R. Daniel, S. Steven, W. Robert et al., "Climate effects of aerosol-cloud interactions," Atmospheric Science, vol. 343, no. 6169, pp. 379-380, 2014.
[16] J. Fan, Y. Wang, D. Rosenfeld, and X. Liu, "Review of aerosolcloud interactions: mechanisms, significance, and challenges," Journal of the Atmospheric Sciences, vol. 73, no. 11, pp. 4221-4252, 2016.

[17] J. Li, R. A. Kahn, J. Wei et al., "Synergy of satellite and groundbased aerosol optical depth measurements using an ensemble Kalman filter approach," Journal of Geophysical Research: Atmospheres, vol. 125, no. 5, 2020.

[18] J. Zeng, M. E. Wang, and H. X. Zhang, "Correlation between PM2.5 concentration and meteorological elements in summer and autumn in Beijing," Chinese Journal of Applied Ecology, vol. 25, no. 9, pp. 2695-2699, 2014.

[19] Y. Zhang, X. W. Jia, X. Yang et al., "Air pollution in typical Chinese cities and its relationship with meteorological parameters," Journal of Meteorology and Environment, China, vol. 33, no. 2, pp. 70-79, 2017.

[20] L. Chen, J. H. Ma, X. R. Zhen et al., "The change characteristics of air pollution in Shanghai and its meteorological factors," Journal of Meteorology and Environment, China, vol. 33, no. 6, pp. 59-67, 2017.

[21] Y. Zhao, Y. Z. Chen, X. Yang, F. H. Chai, and W. Q. Zhang, "Long- term trend and characteristics of PM2.5 in thecentral urban area of Beijing," Ecology and Environmental Sciences, China, vol. 25, no. 9, pp. 1493-1498, 2016.

[22] H. X. Li and X. M. Shi, "Spatial and temporal distribution characteristics and meteorological causes of PM2.5 in xi'an city," Ecology and Environmental Sciences,China, vol. 25, no. 2, pp. 266-271, 2016.

[23] X. C. Liu, H. N. Chen, K. L. Zhao et al., "Analysis of aerosol size distribution and fine particulate matter (PM2.5) concentration in urumqi," Ecology and Environmental Sciences, China, vol. 25, no. 4, pp. 605-613, 2016.

[24] G. Y. Song, J. Jiang, H. Di et al., "Air pollution control and meteor- ological analysis in Hohhot during APEC meeting," Journal of Meteoro-Logy and Environment,China, vol. 33, no. 2, pp. 63-69, 2017.

[25] M. Hu, S. Liu, Z. J. Wu et al., "Effects of high temperature,high relative humidity and rain process on particle size distributions in the summer of Beijing," Environmental Science, China, vol. 27, no. 11, pp. 2293-2298, 2006.

[26] S. Y. Wang, J. T. Jie, X. P. Xiong et al., "Correlation analysis between urban air quality and meteorological conditions," Meteorological Science and Technology, China, vol. 34, no. 6, pp. 688-692, 2006.

[27] T. S. Prancsha and A. K. Kamra, "Scavenging of aerosol particles by large water drops:3. Washout coefficients,half-lives,and rainfall depths," Journal of Geophysical Research: Atmospheres(1984-2012), vol. 102, no. D20, pp. 23947-23953, 1997.

[28] S. Y. Bae, C. H. Jung, and Y. P. Kim, "Relative contributions of individual phoretic effect in the below-cloud scavenging process," Journal of Aerosol Science, vol. 40, no. 7, pp. 621-632, 2009.

[29] M. Mircea, S. Stefan, and S. Fuzzi, "Precipitation scavenging coefficient: influence of measured aerosol and raindrop size distributions," Atmospheric Environment, vol. 34, no. 29-30, pp. 5169-5174, 2000.

[30] L. Zhang, D. V. Michelangeli, and P. A. Taylor, "Numerical studies of aerosol scavenging by low-level, warm stratiform clouds and precipitation," Atmospheric Environment, vol. 38, no. 28, pp. 4653-4665, 2004.

[31] K. F. Li, H. D. Zhang, and Y. H. Xie, "Analysis on precipitation scavenging on PM10 and PM2.5 in central and south of Beijing-Tianjin-Hebei region," Journal of Arid Land Resources and Environment, China, vol. 33, no. 3, pp. 69-74, 2019. 
[32] X. H. Gou, X. Y. Yan, Y. L. Liu et al., "Variation characteristics of atm- ospheric particulate matter concentration in yinchuan area and its relationship with meteorological conditions," Journal of Meteorology and Environment,China, vol. 32, no. 6, pp. 58-68, 2016.

[33] M. Hu, S. Liu, Z. J. Wu et al., "Effects of high temperature, high relative humidity and rain process on particle size distributions," Environmental Science, China, vol. 27, no. 11, pp. 2293-2298, 2006.

[34] H. Q. Kang, B. Zhu, and S. X. Fan, "Size distributions and wet scavening properties of winter aerosol particles in north suburb of Nanjing," Climatic and Environmen Tal Research, vol. 14 , no. 5, pp. 523-530, 2009, in Chinese.

[35] L. Q. Deng, J. Qian, R. X. Liao et al., "Pollution characteristics of atmospheric particulates in chengdu from August to September in 2009 and their relationship with meteorological conditions," China Environmental Science, vol. 32, no. 8, pp. 1433-1438, 2012.

[36] J. M. Xu, W. Gao, and Y. H. Qu, "Observation of the wet scavenge effect of rainfall on PM2.5 in Shanghai," Acta Scientiae Circumstantiae, vol. 37, no. 9, pp. 3271-3279, 2017.

[37] W. W. Pu, X. J. Zhao, and X. L. Zhang, "Effect of meteorological factors on PM2.5 in late summer and early autumn of beijing," Journal of Applied Meteorological Science,China, vol. 22, no. 6, pp. 716-723, 2011.

[38] K. H. Gu, H. C. Shi, S. Zhang et al., "Variation characteristics of PM2.5 levels and the influence of meteorological conditions on chongming island in shanghai," Resources and Environment in the Yangtze Basin,China, vol. 24, no. 12, pp. 21082116, 2015.

[39] Y. Zhang, J. Guo, Y. Yang, Y. Wang, and S. Yim, "Vertical wind shear modulates particulate matter pollutions: a perspective from radar wind profiler observations in Beijing, China," Remote Sensing, vol. 12, no. 3, p. 546, 2020. 